\title{
Mercedes y extranjería entre historia e historiografía: una lectura del poder y la delegación regia en la monarquía católica
}

\section{Royal Grants and Foreignness between History and Historiography: A Reading about Power and Royal Delegation in the Catholic Monarchy}

\section{Fernando Ciaramitaro ${ }^{1}$}

Universidad Autónoma de la Ciudad de México (UACM)

\section{Resumen}

A través de una atenta lectura de Manera de galardón. Merced pecuniaria y extranjería en el siglo XVII, de Victoria Sandoval Parra, se debaten algunos temas actuales de la monarquía de España atados a la historiografía internacional: la merced pecuniaria, la extranjería y el poder del máximo jerarca del imperio, el rey. Igualmente, el libro permite discutir sobre la crisis económica y administrativa del régimen de los Austria y su alternante y dicotómica gestión de las provincias periféricas, entre la descentralización y la centralización de gobierno.

1 Profesor-investigador de dicha universidad. Ha realizado sus estudios posdoctorales en El Colegio de México. Doctor en historia por la Universidad de Catania (Italia).

Contacto: fernando.ciaramitaro@uacm.edu.mx 
Palabras claves: Merced, Extranjería, Monarquía católica, Delegación regia, Poderes del rey

\begin{abstract}
A thorough reading of Manera de galardón. Merced pecuniaria y extranjería en el siglo XVII, by Victoria Sandoval Parra, allows the debate on some current issues of the monarchy of Spain linked to international historiography: pecuniary royal grants, foreignness and the power of the highest ruler of the empire, the king. Likewise, the book also allows the discussion about the economic-administrative crisis of the Austrian regime and its alternating and dichotomous management of peripheral provinces, between decentralization and centralization.
\end{abstract}

Keywords: Royal Grants, Foreignness, Catholic Monarchy, Royal Delegation, King of Spain

$$
* * *
$$

\title{
Introducción
}

El objetivo de esta nota historiográfica y temática -tal vez una amplia reseña crítica- consiste en aportar algunas consideraciones teóricas acerca de la reciente investigación histó-

252 rica que trata sobre la merced, la extranjería, el poder regio y sus formas derivativas en la monarquía de España. La ocasión surge por el libro de Victoria Sandoval Parra, Manera de galardón. Merced pecuniaria y extranjería en el siglo XVII, publicado por el Fondo de Cultura Económica y la Red Columnaria.

Raras veces se tiene el placer de leer un aporte tan novedoso a la historiografía iberoamericana y a la historia imperial, una 
indagación seria, puntual, documentada y compleja porque abarca un universo historiográfico interdisciplinario: el derecho, la sociedad, las instituciones (los cuerpos), la política y la economía. En el centro de su análisis se encuentran la merced regia y numerosos solicitantes extranjeros (balcánicos, norteafricanos y británicos) que deseaban acceder a la gracia del monarca de las Españas y que, asimismo, permiten al leedor especular acerca de otros argumentos, como el poder y sus representaciones simbólicas y arbitrarias, la hacienda imperial, el gobierno central y periférico y la ideología.

En el título del volumen el siglo XVII queda pero muy corto: el estudio -dividido en dos partes, la primera es teórica y la segunda se enfoca en la práctica administrativa de la merced-empieza en la época medieval y solo por las referencias documentales se circunscribe a la segunda mitad del siglo XVI y al siglo XVII.

¿Cuáles son las características jurídicas y formales más sobresalientes de la soberanía, de la extranjería y de las mercedes en la monarquía española? ¿Cuáles son sus modalidades operacionales? ¿Cuáles las consecuencias socioeconómicas de su praxis? ¿Cómo las dádivas pecuniarias permiten deslumbrar una presunta modernización o, al revés, una crisis imperial sistémica? Se intentará dar respuesta a estas inquietudes para contribuir a esclarecer algunas facetas socioinstitucionales típicas del imperio hispánico.

\section{Soberanía, vasallaje, extranjería y merced}

Victoria Sandoval Parra empieza analizando la soberanía y su reverso: la condición subordinada del vasallo (con sus diferentes formas en el señorío: el criado, el servidor de la casa, 
el caballero, el militar, el consejero, el tributario)2; “combinación entre tácticas políticas y peripecias personales, entre estructuras de la monarquía y situación personal de los que aspiran a ser súbditos o como tal se postulan"; el sujeto, individual o colectivo, que anhela el amparo del monarca al mismo tiempo busca seguridad y tuición (Sandoval Parra 2014: 12). E insiste en las continuas crisis financieras del periodo 1570-1700 que fueron, a la postre, las dificultades estructurales de la política y la gobernanza, que empeoraron las disfunciones españolas en el contexto internacional y generaron nuevos modales de protección económica y auxilio político de los migrantes, forzados o voluntarios, que ambicionaban el socorro del rey.

Los problemas tratados - como asegura Sandoval Parra justificando el meollo de su tesis- pueden analizarse como:

[...] circulación de condicionamientos y determinaciones de abajo arriba, como de arriba abajo, y en definitiva es natural pensar que tales escalones de las más altas instituciones, las instituciones intermedias y los contingentes humanos, se encuentran intercomunicados e intercondicionados, en un sentido u otro, y que de la circulación de las decisiones y la gravedad de las circunstancias que afectan a tales elementos derivan consecuencias que afectan a las circunstancias y decisiones del resto de sujetos políticamente relevantes (Sandoval Parra 2014: 14-15).

2 Francisco J. Aranda Pérez (2012: 51-84) aclara las dos nociones claves del vínculo vasallático, el servicio y el beneficio, y resalta la cualidad de la "confianza", o sea, la mutua y siempre asimétrica lealtad existente entre el señor y el súbdito. 
Así, la merced otorgada como apoyo económico a extranjeros, residentes en el imperio o entre los enemigos, es un patrocinio que tiene que ser examinado a partir de la metodología decidida por la cúspide de gobierno, el soberano, su corte y los consejos, según la praxis del ejercicio de la potestad y sus condicionantes corporativos ${ }^{3}$. La gracia depende del ánimo y altruismo del soberano, refleja su misericordia y se ejerce con una flexibilidad que permite solucionar condiciones ceñidas y enmarañadas. Representa una excepción jurídica, que, sin embargo, se ejecuta ininterrumpidamente, confirmando una condición permanente en el pensamiento, la gestión, la concesión, el desenvolvimiento y la eventual revocación (parcial o total). Es una clave más de la justicia absoluta del rey, que a través de su actuación se normaliza en el verificarse constantemente. Esa opción excepcional regularizada se distribuye también a través de la representación política; consejeros, virreyes, ministros y otros actores de la voluntad regia pueden dar mercedes. Ese acto de generosidad de la maquinaria monárquica refleja la esencia de una justicia distributiva propia de la gracia "en su calidad de donación causal", que percibe una profunda y subjetiva razón de mérito que, empero, nunca elimina su naturaleza jurídica "graciosa".

A lo largo del texto se ofrece un sinnúmero de lecturas acerca de la merced; sin embargo, me inclino por la interpretación de la merced como característica mística, sagrada y polivalente del poder real. La merced es así una fórmula regia que se mueve al margen de las vías ordinarias de la justicia; es una potestad mayor y excepcional del monarca, que puede ejercerla por su condición de representante terrenal de

3 Sobre el absolutismo del rey de España y su poder de justicia, véase Fernando Ciaramitaro (2015: 51-58). 
Dios $^{4}$. La merced es un poder que conlleva un cuadro teórico y práctico de excepción jurídica permanente ${ }^{5}$.

Después de describir los prolegómenos medievales del instituto y de la praxis de la gracia y, en particular, el vínculo que los sucesores al trono tienen que acatar en relación con las mercedes y las donaciones concedidas por los anteriores monarcas, la autora cita al jurisconsulto medinense Jerónimo Castillo de Bovadilla y su Politica para corregidores (1597) para resaltar el fundamento de la obediencia al dictado del predecesor y la obligación que tiene el monarca reinante de cumplir con el derecho, el ejemplo, la obediencia de los súbditos y la seguridad de la justicia ${ }^{6}$. Se justifica tal actitud con la unidad del imperio y los preceptos de la monarquía. Por esas razones -explica Sandoval Parra (2014: 95-99)- la dispensatio o derogación es una excepción, porque, de preferencia, los príncipes tienen que respetar el ius adquisitum.

4 Véase Enrique Álvarez Cora (1998: 95-97), entre otros posibles ejemplos.

5 Considero provechoso el concepto historiográfico de excepción permanente que la filosofía y la filosofía de la historia brindan a los historiadores -no exclusivamente a los contemporaneístas- por la oportunidad de argumentar acerca de la "precariedad" e "incertidumbre" del derecho, véanse, por ejemplo, las originales pesquisas de Wolfgang Kaiser (2008; 2008a). Por otra parte, también sería útil analizar el concepto de excepción permanente en la filosofía política y en la filosofía de la historia de Giorgio Agamben (2003: 10-11, 19, 34-43) y trasladar sus aseveraciones acerca del derecho público, el derecho internacional, la contingencia política, el orden jurídico, la vida, la necesidad y la temporaneidad a la época moderna.

6 La Politica para corregidores es un escrupuloso manual para ejercer con éxito el gobierno y marcó la historia del pensamiento político en el mundo hispánico sobre algunos temas neurálgicos como la religión, la justicia, el origen y legitimidad de la autoridad de los príncipes (González Alonso, 1981: 85-136). 
Sandoval Parra asevera que Carlos $\mathrm{V}$ fue quien ahondó aún más en la disciplina de la merced y a través de una ordenanza se estableció que se hacía merced de oficio o pena solo cuando el oficio quedaba vacante y la pena estaba impuesta con sentencia definitiva. Además, se vinculó la merced de bienes y dinero a la cámara del rey. Luego, narra lo que pasó en la época de Felipe III con las prerrogativas de la cámara de Castilla. Todas esas consideraciones sirven a la historiadora para demostrar la paulatina burocratización del proceso de otorgamiento de gracias y mercedes y la regularización del procedimiento a través de un expediente. Las mercedes en el ancien régime se fundamentan y estandarizan como instrumentos de justicia por el recurso de suplicación ante el Consejo real. Existen así unos requisitos específicos, formales y volitivos (memorial, comprobación de la causa meritoria, expedición cancilleresca de provisión, exclusión del engaño o de la obrepción, etcétera) que "se combinan en causas de reforma con color de revocación, anulación, moderación, extinción, a menudo difíciles de distinguir, porque procuran en definitiva una misma finalidad, cual es la retroacción en el ejercicio de la merced y la exclusión o alteración de sus efectos" (Sandoval Parra 2014: 136).

Para estudiar el funcionamiento práctico de la merced, Sandoval Parra (2014: 154-158) recurre a una vasta documentación administrativa depositada, concretamente, en el Consejo de estado. Cita a Tamar Herzog $^{7}$ y es interesante su manera sutil de criticarla (conjetura que comparto); si bien le

7 Sus aportaciones acerca de la vecindad, la extranjería y la nación son indispensables; véase, por ejemplo, Herzog (2003), cuya traducción al castellano, Vecinos y extranjeros. Hacerse español en la edad moderna, ha sido editada por Alianza en 2006; véase, además, Herzog (2011: 21-31). 
reconoce el haber subrayado el papel del catolicismo como aglutinador del estado hispánico, señala la tal vez simplista y mecánica descripción del pasaje socio-jurídico-procedimental "desde la regularización de las diez formas de adquisición de la naturaleza por parte de este cuerpo legal, a la preferencia por las formas de nacimiento (y acaso la ascendencia) y la residencia (enlazada al domicilio y la vecindad) en la doctrina y legislación"; la anotación radica en la necesidad de profundizar no solamente en la "alteración evolutiva de razones materiales" o formales de adquisición de la naturaleza (otra merced real), sino también en la condición misma del natural entre privilegio y norma ${ }^{8}$. En efecto -y eso lo agrego yo- el convencimiento personal no es suficiente frente a la certeza del derecho, no obstante la profesión de fe, el servicio militar, administrativo o artístico al rey, el vasallaje, la crianza, el matrimonio y el dominio, la residencia prolongada en una provincia del imperio, con el animus habitandi? Todas, carac-

8 Además de las consideraciones fácticas de Tamar Herzog, la discusión teórica acerca de la diferencia entre el vecino de la edad moderna y el ciudadano de la contemporaneidad presume un discernimiento definitorio ceñido: el primero es un hombre enraizado y con filiación territorial y gremial (en América también racial; en Europa occidental menos), mientras que el segundo es parte de una comunidad abstracta, que cobra sentido en una colectividad nueva, la nación decimonónica. Ha sido, entre otros, François-Xavier Guerra -reelaborando las conclusiones de Pierre Rosanvallon- quien ha caracterizado al ciudadano moderno por sus propiedades de individualidad, igualdad, universalidad y abstracción, atributos que para realizarse encuentran tutela en las constituciones de los estados americanos; véanse Rosanvallon (1999: 12) y Guerra (1999: 42).

9 Lo explica el estudio de Fabricio Gabriel Salvatto (2013) que, mirando a la conversión de la vecindad corporativa rioplatense en ciudadanía abstracta, descubre cómo los mecanismos de construcción de la ciudadanía dependen de las añejas relaciones príncipe-súbditos y cómo las metodologías de la gracia real son remplazadas por las de las autoridades 
terísticas y condiciones jurídicas objetivas que nunca dejaron de ser relevantes para la concesión regia del privilegio de naturaleza durante los siglos XVI, XVII y XVIII ${ }^{10}$. Sandoval Parra dice que estaba en juego la imagen exterior del rey católico por su política confesional desde la segunda mitad de la centuria decimosexta y durante toda la centuria siguiente; pero ese inicio de grandeur, de esplendor más político que religioso, es anterior: la anexión de Granada, los viajes colombinos, la conquista de Nápoles y Navarra y la sucesión de Carlos de Habsburgo hacen de la monarquía el centro del mundo. La primera proyección universal de España es

constituyentes, que se imputan, entre 1815 y 1819, a una representación nacional.

10 Como se ha atestiguado en otros lares (Ciaramitaro y Reyes Lugardo, 2017), los dos conceptos de subjetividad identitaria e identidad legal, si bien poseen elementos comunes, tienen funciones diferentes y conforman lógicas y formas jurídicas distintas. En efecto, la subjetividad identitaria tiene consecuencias en la vida cotidiana porque conlleva la aplicación de reglas jurídicas, mientras que la gracia, también herramienta jurídica, aplica una lógica no silogística, pero equitativa: la gracia se contrapone a la praxis jurídica porque excepción jurídica inspirada por un sentido distinto del de las normas y que opera y es válida porque insertada en el más vasto conjunto de reglas del ordenamiento jurídico, que nunca se limita al conjunto de los cánones escritos. El instituto de la gracia desarrolla una significativa función de complementación de la legislación ordinaria, así, mientras que el rey o las entidades delegadas por él no estén listas en la preparación de una "codificación" ad hoc, se aplican entonces las disposiciones "excepcionales" que siempre revisten un papel de legalidad. Tamar Herzog (2011: 26-27, 30-31) afirma que las condiciones jurídicas de natural o extranjero en el imperio hispánico no eran concretas, más bien hacían patente solo la existencia de un continuum de situaciones jurídicas que componía una escala de formas intermedias con dos extremos: el totalmente natural y el totalmente extranjero. De aquí surge la confusión: el involucrar la subjetividad identitaria con la disposición normativa. 
anterior a la reforma protestante y el proceso de centralización y modernización del aparato estatal empieza con Isabel de Castilla y Fernando de Aragón ${ }^{11}$; la política en defensa y expansión de la catolicidad es coetánea de la época de los reyes católicos; lo demuestran los decretos de expulsión de los judíos y las muchas conversiones y naturalizaciones de musulmanes durante las últimas décadas del siglo XV.

\section{Merced pecuniaria y causa meritoria: entre la modernización y la "penuria" imperial}

Después de enlistar las tipologías de merced pecuniaria y algunas figuras afines, como el entretenimiento (gracia de contenido pecuniario de carácter indefinido), la ayuda de costa (pago fijo que se salda una sola vez), la ventaja (sobresueldo respecto de un estipendio común), la limosna (merced asignada de una vez o fraccionada en el tiempo) ${ }^{12}$, la plaza doble (dádiva que duplica la paga correspondiente a plaza militar ordinaria que ocupa el solicitante) y la plaza muerta (pensión por incapacidad o indisposición física) y otras subvenciones concedidas a forasteros que no comportaban gastos para la corona -carta de recomendación, patrón de bautizo y pasaporte-, Sandoval Parra se detiene en la causa meritoria; sus claves son el honor y el servicio y a ese segundo elemento le corresponde asimismo el peligro tomado, que asienta el

11 Entre la inmensa bibliografía, véanse John H. Elliott (1963), Miguel Artola (1999) y, específicamente, para el autoritarismo monárquico de Fernando el Católico y los diferentes intereses estratégicos de los reinos de Castilla y Aragón, Jaime Vicens Vives (1966: 106-108).

12 Las limosnas dependían del cargo de limosnero mayor, o sea, el oficial eclesiástico del palacio del rey, que desde el reinado de Felipe II residía en la corte (AGS, Casa y Sitios Reales, legajo 110, n. 632). 
valor del suplicante. Luego, observa las obligaciones del favorecido y la tramitación administrativa de la merced pecuniaria: los deberes del perceptor de una merced pecuniaria eran, esencialmente, el de presentación en el lugar de cobro, el mantenimiento del domicilio en el mismo distrito y el desempeño del servicio. La única excepción es representada por la plaza muerta; en ese caso no hay obligación de servicio, que se realizó cuando el sujeto estaba en buenas condiciones de salud (Sandoval Parra 2014: 202-204).

¿Solo los hombres negociaban con la corona una gracia pecuniaria? La respuesta -según Sandoval Parra (2014: 243256) - es negativa: no obstante predominasen los varones sobre las mujeres como pretendientes a una merced, ellas generalmente aportaban en las peticiones algunos rasgos comunes de su género, por ejemplo, la fragilitas o, para las viudas, la imbecillitas sexus ${ }^{13}$.

Ahora bien, todos esos aspectos son muy útiles para el debate historiográfico acerca de la modernización de la administración de la monarquía hispánica: el sistema de las mercedes se estandariza con mecanismos regulares $\mathrm{y}$ procedimentales, la merced se convierte en un instrumento más de la maquinaria burocrática del estado. Se agrega que la merced pasa de un régimen de ajuridicidad a la completa juridicidad y se menciona, para dar fuerza al discurso, entre otros, a José María García Marín (1992: 34-53); se reconoce centralidad a las Siete partidas en la gestión burocrática como instrumentum regnis y para la época moderna se recalca el sur-

13 Sobre la presunta mollitia mentis de las mujeres y muchas otras expresiones similares, como imbecillitas sexus o infirmitas sexus, presentes en textos romanísticos, véase Eva Cantarella (1989). 
gimiento de una monarquía administrativa vinculada a la idea organicista de la política, que encuentra en el rey la cabeza efectiva del poder y el centro desde el cual se desprenden los numerosos brazos que permiten el funcionamiento de la compleja máquina del imperio. No obstante esas interesantes afirmaciones, el proyecto de modernización -creo- es solo aparente y la autora lo reconoce en las páginas finales, cuando al referirse al problema de la descentralización de la merced regia concluye que en el sistema de otorgamiento de mercedes existió una contradicción evidente: de un lado, el deseo de reglamentación del iter y, de otro, los "usos irregulares impulsados expresa o tácitamente o no debidamente fiscalizados" (Sandoval Parra 2014: 410). Fue el caos: en lugar de concentrar el colapso, en la corte resultó más viable un quebrantamiento difundido, política y territorialmente, también en las varias periferias. Las decisiones de una política ambigua y atormentada edificaron "un sistema asistemático, una construcción ya originariamente deconstruida" (Sandoval Parra 2014: 411).

Se tocan magistralmente otros temas cardinales, como la condición del suplicante extranjero, su profesión (las armas y las letras) y la reformación o aclaración de la merced pecuniaria. Reformar la merced significaba suprimirla o reducir la cuantía. El parecer volitivo del soberano fundamentaba cual-

262 quier concesión de merced y cuando este juicio desaparecía o se alteraba, el rey podía revocar su concesión graciosa. Asimismo, el detrimentum regni era un factor determinante en la valoración discrecional del monarca ${ }^{14}$. Esas consideraciones

14 Resulta ejemplar la "obstinación generosa" de Felipe III que, en detrimento de las cajas reales y en contra del parecer del Consejo de Italia, en 1613, insistió en su acto gracioso consistente en una ayuda de cos- 
conllevan a la historiadora a especular sobre la concesión de las mercedes y sus planteamientos teóricos. Con el consentimiento de la gracia regia se proyectan dos condiciones del instituto, de un lado, la voluntad propia del monarca, de otro, la estandarización administrativa de un procedimiento ancorado al sistema imperial de la monarquía, que consiente la vigilancia de la misma concesión.

Mientras que la merced y su empleo en la administración de gobierno permiten la formulación de una teoría jurídica general, no se puede hacer lo mismo en relación con los fundamentos hipotéticos de su reformación o aclaración, porque mientras la coyuntura de la concesión graciosa era potencial, la razón de la alteración se relaciona con escenarios nuevos y concretos, inconvenientes determinados que trasforman la situación

ta para Pedro Téllez-Girón y Velasco Guzmán y Tovar, III duque de Osuna, virrey siciliano en 1610-1616. Así, el consejo en su consulta al rey: "Este decreto se ha visto en Consejo, y cuando se hizo esta consulta se ponderaron en el los inconvenientes que avia en dar ayuda de costa al duque como lo proponia el Parlamento, y assí en lugar del ayuda de costa propuso el Consejo la pension de los seys mil escudos de que Vuestra Magestad haze agora merced al duque, y al Consejo no puede dexar de confirmarse de nuevo en el mismo parecer que no convenga tratar de ayuda de costa, estando ya concedida por Vuestra Magestad esta pension, que es de las mayores que se hayan dado por el a ningún virrey de los estados de Italia, porque verdaderamente el estado presente del Patrimonio de Sicilia no da lugar a otra cosa [...]". Y así la contestación pertinaz del monarca, ciego del problema del detrimentum: "Densele de ayuda de costa los 40000 que se diçe en la consulta inclussa, que se pueden sacar de aquellos ofiçios sin perjuicio de mi haçienda y embiensele a el duque los despachos desto y de la merced de los 6000 ducados de renta que le tengo hecha con nueva orden de la execuçion de lo resuelto en lo de Meçina” (AGS, Secretarías provinciales, legajo 993, libro 719, ff. 180-180v). 
sin planteamiento previo de distorsión del sistema. Vence la política, la ragion di stato, el cambio se da por necesidad económica de salvar el reino. Sandoval Parra señala que no se puede erigir un marco teórico en el caso de la reformación, pero, tal vez, la justificación teórica se encuentra en la no generación de un derecho adquirido con el instituto jurídico de la merced pecuniaria. En efecto, más adelante, habla de la ambigüedad jurídica de la reformación de la merced (Sandoval Parra 2014: 384). De hecho, la cuestión del detrimentum es persistente en la literatura económico-forense hispánica desde el siglo XV, pasando por los arbitristas y hasta las centurias XVIII y XIX ${ }^{15}$. Por ejemplo, todavía en 1732, el jurista Antonio de Contreras (1732: 634) atestiguaba que: "Nec Principes possunt vendere, nec concedere redditus super tributis, seu vectigalibus imposit. Cum sit alienatio perpetua, \& verè, \& realiter commodis tributorum priventur in gravissimun detrimentum Regni, benè tamen possunt Reges tempore necessitatis hos redditus nos solvere in partem, aut in totum, aut gratias suspendere, sicut possunt concedere moratorias suis subditis".

La querella fue vivísima entre finales del siglo XVI e inicios del XVII, como lo demuestra Sandoval Parra (2014: 395411) en su pormenorizado razonamiento acerca de la reformación del instituto de la merced en las Ordenanzas militares de 1598, 1603 y 1611: se trastorna su tipología, su misma

264 noción, y se realiza una mutación en las situaciones retributivas. El conflicto entre la mayor incidencia de la voluntad del rey y la descongestión burocrática comporta una "crisis sistémica” de la merced pecuniaria. El asunto de la liquidación

15 Sobre la conciencia de la decadencia, sus síntomas, los medios propuestos para combatirla y las apelaciones al monarca en los años 1600-1620, véase Bartolomé Bennassar (2006: 63-79). 
de la merced reviste así, otra vez, un peso teórico: el pago efectivo de las mercedes, no obstante la centralización más o menos real de los mecanismos administrativos, estriba en la funcionalidad de la delegación regia, porque el pago debe originarse en el lugar del servicio y este se halla política o militarmente partido por las comarcas del imperio. Así, supuestamente, la estimación de que el gobierno local sea un instrumento ordinario de ejecución podría percibirse como una asumida apreciación de que toda intervención local depende de una sanción anterior o posterior de la corte. Y cuando el régimen económico o de gestión está a punto de colapsar, la medida de descentralizar el fallo de la concesión de la gracia regia en los que poseen funciones ejecutivas en los territorios periféricos resulta sin duda sensato, no obstante las normas -que empujan en la dirección contraria-intentaron desesperadamente rescatar la bondad del sistema ordinario, o sea, la centralidad. Es la contradicción administrativa y de gobierno que mencioné antes y que la autora apunta.

\section{Conclusión}

La acabada muestra presentada por Victoria Sandoval Parra de las dádivas pecuniarias de la monarquía ha demostrado la función pragmática de esa poderosa herramienta de la línea imperial del rey de España, directriz de gobierno para la construcción de un consenso amplio e incluyente, para cooptar a súbditos y foráneos a la política nacional e internacional en defensa de la verdadera fe y de cualquier otro interés, militar o diplomático. Además, desde la perspectiva inversa, la del favorecido, hay que agregar que gracias a su abnegación se mejoró la condición de la corona en los ajedreces mediterráneo y europeo y -como subraya José Javier 
Ruiz Ibáñez (2011) - los amparados de la monarquía católica soldaban por definición la movilidad geográfica con la social, intentando guardar u optimizar sus condiciones socioculturales con la valorización de sus sacrificios, el dolor o la traslación de la posición ocupada anteriormente en la nueva comunidad de acogida ${ }^{16}$.

Indudablemente Manera de galardón deja una huella indeleble en la historia de la monarquía católica. De aquí brotarán sugestivas y edificantes controversias, no solo con relación al ánimo gracioso del rey hacia los extranjeros sino, en general, sobre la función del poder de la corona y sus implicaciones u objeciones imperiales.

Recibido: 25 de junio del 2016

Aprobado: 11 de noviembre del 2016

\section{Bibliografía}

AGAMBEN, Giorgio

2003 Stato di eccezione. Homo sacer, II, 1. Turín: Bollati Boringhieri.

ÁLVAREZ CORA, Enrique

1998 La producción normativa bajomedieval según las compilaciones de Sicilia, Aragón y Castilla. Milán: Giuffrè.

ARANDA PÉREZ, Francisco J.

2012

"Servir a quién, en qué y cómo: vasallos en la política hispánica moderna”. En ESTEBAN ESTRİNGANA, Alicia (editora). Servir al rey en la Monarquía de los

16 En relación con los argumentos citados y el lazo entre dignidad y exilio en la administración de la potestad del rey de las Españas, véase José Javier Ruiz Ibáñez (2011). 
Austrias. Medios, fines y logros del servicio al soberano en los siglos XVI y XVII. Madrid: Sílex, pp. 51-84.

ARTOLA, Miguel

1999 La monarquía de España. Madrid: Alianza.

BENNASSAR, Bartolomé

2006 La monarquia española de los Austrias: conceptos, poderes y expresiones sociales. Salamanca: Universidad de Salamanca.

CANTARELLA, Eva

1989 "La vita delle donne". En GABBA, Emilio y Aldo SCHIAVONE (editores). Storia di Roma. Turín: Einaudi, vol. 4 (Caratteri e morfologie), pp. 557-608.

CASTILLO DE BOVADILLA, Jerónimo

1775 [1597] Politica para corregidores, y señores de vasallos, en tiempo de paz, y de guerra, y para jueces eclesiasticos y seglares [...]. Madrid: Imprenta Real de la Gazeta, 2 volúmenes.

CIARAMITARO, Fernando

2015 "Autonomías y dependencias de poderes en la monarquía católica: rey, Consejo de Indias, virrey y audiencia de México entre pensamiento político y práctica de gobierno (siglos XVI-XVII)". Storia e politica, VII: 1, pp. 45-86.

CIARAMITARO, Fernando y Marco A. REYES LUGARDO

2017 "España y América entre extranjería, integración, esclavos e indígenas: algunas consideraciones historiográficas". Andamios. Revista de investigación social, 14: 33, pp. 241-272.

CONTRERAS, Antonio de 1732 Medula iuris, in varijs, et de iure competente fisco. Madrid: Gabrielem del Barrio. 
GARCÍA MARÍN, José María

1992 Monarquía católica en Italia. Burocracia imperial y privilegios constitucionales. Madrid: Centro de Estudios Constitucionales.

GONZÁLEZ ALONSO, Benjamín

1981

Sobre el Estado y la administración de la Corona de Castilla en el Antiguo Régimen. Las Comunidades de Castilla y otros estudios. Madrid: Siglo XXI.

GUERRA, François-Xavier

"El soberano y su reino. Reflexiones sobre la génesis del ciudadano en América Latina". En SABATO, Hilda (coordinadora). Ciudadanía política y formación de las naciones. Perspectivas históricas de América Latina. México: El Colegio de México, Fondo de Cultura Económica, pp. 33-93.

ELLIOT'T, John H.

1963 Imperial Spain, 1469-1716. Londres: E. Arnold.

HERZOG, Tamar

2011 "Naturales y extranjeros: sobre la construcción de categorías en el mundo hispánico". Cuadernos de Historia Moderna, 10, pp. 21-31. https://doi.org/10.5209/ rev_chmo.2011.38668

2003 Defining Nations. Immigrants and Citizens in Early Modern Spain and Spanish America. New Haven-Londres: Yale University Press (traducción al castellano: Vecinos y extranjeros. Hacerse español en la edad moderna. Madrid: Alianza, 2006).

KAISER, Wolfgang (editor)

2008 Le commerce des captifs. Les intermédiaires dans l'échange et le rachat des prisonniers en Méditerraneé, XVe-XVIIIe siècle. Roma: Ecole Française de Rome. 
2008a "La excepción permanente. Actores, visibilidad y asimetrías en los intercambios comerciales entre los países europeos y el Magreb (siglos XVI-XVII)". En MARTINEZ TORRES, José Antonio (editor). Circulación de personas e intercambios comerciales en el Mediterráneo y en el Atlántico (siglos XVI, XVII, XVIII). Madrid: Consejo Superior de Investigaciones Científicas, pp. 171-190.

ROSANVALLON, Pierre

1999 La consagración del ciudadano. Historia del sufragio universal en Francia. México: Instituto Mora.

RUIZ IBÁÑEZ, José Javier

2011 "Servir segundo a dignidade: exilios políticos e administraçao real na monarquía hispánica, 15801610". En BENTES MONTEIRO, Rodrigo y otros (editores). Raízes do privilégio. Mobilidade social no mundo ibérico do Antigo Regime. Rio de Janeiro: Civilização Brasileira, pp. 105-132.

SALVATTO, Fabricio Gabriel

2013 "La gracia real bajo la forma republicana en el Río de la Plata. Vecindad y naturaleza en el litoral rioplatense (1808-1824)". Diacronie. Studi di Storia Contemporanea, 16: 4. Consulta: 25 de mayo de 2017.

http:/ /www.studistorici.com/2013/12/29/salvatto_ numero_16/.https://doi.org/10.4000/diacronie.940

SANDOVAL PARRA, Victoria

2014

Manera de galardón. Merced pecuniaria y extranjería en el siglo XVII. Madrid: Fondo de Cultura Económica, Red Columnaria.

VICENS VIVES, Jaime

1966 Profilo della storia di Spagna. Turín: Einaudi.

Fuentes de archivo

AGS Archivo General de Simancas, Valladolid (España). 